\title{
Scanning Electron Microscopy
}

Volume 1986 | Number 2

Article 29

5-5-1986

Corrosion Cast Technique Applied in Lymphatic Pathways

A. Castenholz

University of Kassel

Follow this and additional works at: https://digitalcommons.usu.edu/electron

Part of the Biology Commons

\section{Recommended Citation}

Castenholz, A. (1986) "Corrosion Cast Technique Applied in Lymphatic Pathways," Scanning Electron

Microscopy. Vol. 1986 : No. 2 , Article 29.

Available at: https://digitalcommons.usu.edu/electron/vol1986/iss2/29

This Article is brought to you for free and open access by the Western Dairy Center at DigitalCommons@USU. It has been accepted for inclusion in Scanning Electron Microscopy by an authorized administrator of DigitalCommons@USU. For more information, please contact digitalcommons@usu.edu.

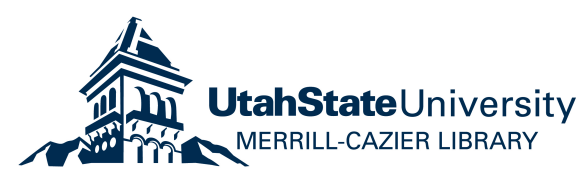


SCANNING ELECTRON MICROSCOPY/1986/II (Pages 599-605)

A. Castenholz

\author{
Human Biology \\ University of Kassel \\ Heinrich-Plett-Strasse 40 \\ D-3500 Kasse] \\ W. Germany \\ Phone No. 05618044356
}

(Received for publication February 15, 1986: revised paper received May 05, 1986)

Abstract

The paper deals with methods and results of the microcorrosion cast technique in lymph angiology. For the representation of the special organization of the lymph vascular system including the initial vascular structures, intranodal pathways, bigger collectors, and lymph trunks, the application of various injection techniques is necessary. The interstitial injection of Mercox ${ }^{R}$ proves to be suitable to show the initial lymphatics and prelymphatic spaces. Similarly, the intranodal injection makes visible the system of the lymph sinuses and the spaces of the reticular tissue in this organ. Casts of bigger collecting vessels, lymph trunks, and thoracic duct can be obtained by direct injection of the resin into the vascular lumen. Thus, these techniques enable to make visible the structural details of the cast preparations of all parts of the lymphatic system.

KEY WORDS: Corrosion casts, Lymphatic Pathways

\section{Introduction}

The lymphatic vascular system does not represent a "closed circulatory system" like that of the blood vessels. The lymphatics begin "blindly" with a plexus-like initial part from which the lymph is drained off in the collecting channels with a lot of lymph nodes. Bigger lymph trunks collect the lymph of the whole body which unite in the venous side of the blood circulation (fig. 1). The intraluminal injection of resin commonly used in blood angiology to obtain corrosion casts from arteries, veins, and terminal blood vessels becomes effective in the lymph vascular system only in the central part, which consists of bigger collectors and lymph trunks. To get casts from the smaller collectors and the intranodal and initial lymphatic system another technique, the interstitial injection of resin, has to be applied. This method can also be tried to show the prelymphatic tissue spaces.

Till now, numerous investigations have used the corrosion cast technique for the representation of the blood vascular system in scanning electron microscopy (SEM) (review of 1iterature see Lametschwandter et al.14). Only a few papers dealing with casts of 1 ymphatics have been published11-13,16,17. Our own experience with the corrosion cast technique in such a particular field as lymph angiology derives from observations of the subepithelial initial lymphatic plexus in the rat tongue and of the mesenteric lymph nodes, lumbal lymph trunks, and thoracic duct in rat and rabbit4-6. Some studies have been made under special experimental conditions, i.e. using high interstitial pressure or the injection of colloidal carbon into the tissue ${ }^{4}, 9$. Further investigations considered the ontogenetic aspect 8,10 . The present paper describes the different ways of casting the lymphatic vascular tissue and its representation in SEM. It also tries to give a comparison between 
the morphological features reproduced by the casts and the vascular structures found in common tissue preparations.

\section{Materials and Methods}

Wistar rats and rabbits are used in our studies. The anesthetized animal is killed and exsanguinated after thoracotomy and a cut through the heart. No further pretreatments precede the injection of the resin into the tissue. We use in all studies the methylmethacrylate Mercox (Japan Vilene Co. Tokyo) according to the directions of the producer. The high liquidity of this substance proves to be especially advantageous for casting the complicated system of the initial and intranodal lymphatic pathways. To demonstrate the initial lymphatics we chose the tongue of the animals because this organ proves to be very suitable for our experiments: it can easily be reached for injections and other treatments, even in the living animal. The resin is injected interstitially into the tongue body and is afterwards dispersed in the tissue by a gentle massage of the organ with a small glass rod. For a sufficient filling of the tongue we need $0.3-0.5 \mathrm{ml}$ Mercox ${ }^{R}$ in adult rats and $1.0-1.5 \mathrm{ml}$ in rabbits of $2-4 \mathrm{~kg}$ body weight.

For the representation of the intranodal lymph pathways in SEM we inject the resin directly into the $1 \mathrm{ymph}$ nodes of an organ like the mesentery. For this purpose the abdominal cavity is opened and the gut with the mesentery is exposed. In order to fill predominanty the intranodal sinuses the needle is inserted exactly into the subcapsular space of the manginal sinus. The quantity of the resin has to be low. Injections with a higher amount of Mercox ${ }^{R}$ produce preparations in which both system - that of the intranodal sinuses and that of the spaces of the reticular tissue - are filled. Depending upon the size of the lymph node and mode of injection $0.2-0.5 \mathrm{ml}$ resin are used for one node.

The bigger collecting lymph channels, i.e. the lumbal trunks and the thoracic duct, are cast by intraluminal injection; the hypodermic needle is introduced into the vessel in the direction of the $1 \mathrm{ymph}$ flow. Several microliters of resin are necessary for casting the whole lymphatic vascular system to the angle of the jugular vein in rabbit. In rat we obtain the same results with a smaller quantity of resin.

All injections are made by hand with moderate pressure. The cast tissue is removed after hardening of the resin which takes about 5-10 minutes and then fixed in $2.5 \%$ glutaraldehyde for two days. The fixed preparation is macerated in a saturated solution of potassium hydroxide at a temperature of $40^{\circ} \mathrm{C}$, washed under rinsing water and posttreated in 10\% hydrochloric acid. Thereafter the specimen is washed in bidistilled water, air-dried, mounted on stubs with conducting carbon, and sputtered with gold. The casts are then examined in the AMR 1200 scanning electron microscope (E. Leitz, W. Germany) at an accelerating voltage of $5-15 \mathrm{kV}$.

\section{Results}

Prelymphatic Pathways and Initial Lymphatics

By the "interstitial injection method" cast preparations of the tongue are obtained in which two systems are filled with the resin: the tissue spaces with the prelymphatic channels and the true initial lymphatics (fig. 2). In tissue preparations of the tongue the initial lymphatics are lined with a continuous endothelial layer forming tubes of varying diameters in the range of 15 to $60 \mathrm{\mu m}$. The shape of the interstitial spaces not bordered by a special cellular sheet is of great variety in casts depending on the kind of tissue to which they belong. In loose connective tissue or mesenchyma they exhibit roundand oval-shaped figures or squamous structures (fig. 3). In dense fibrous tissue they show small, bar- or thin sheet-like figures interweaving to a complicated system. Other cast patterns consisting of bizarre plates and extended formations appear in skeletal muscle and glands due to the special stromal and parenchymal differentiation of these organs (for details see Castenholz 7 ).

Size and dimensions of the interstitial cast structures are somewhat dependent on the filling pressure applied. Thus, single structural elements may become broader and often represent extensive complexes if the injection is done at high pressure. In the living tissue, the interstitial spaces contain the interstitial fluid which partly reaches the initial lymphatics which are basically involved in the process of lymph formation. However, it is difficult to decide from SEM micrographs alone whether all the interstitial cast structures are to be considered prelymphatic pathways .

The initial lymphatics can clearly be differentiated from the cast of interstitial spaces owing to their tubelike appearance and plexus-like arrangement (fig. 4). At some sites of the lymphatic plexus sac-like outpocketings can be found indicating the blind beginnings of the initial lymphatic system. Direct connections between the 

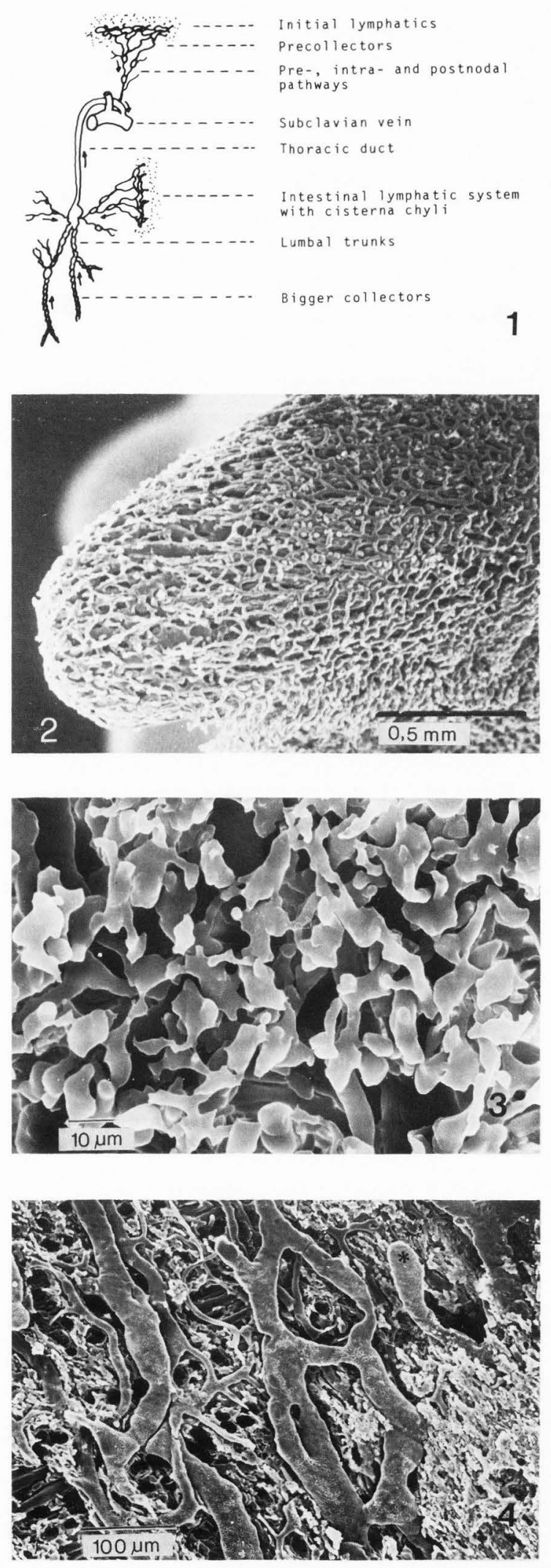
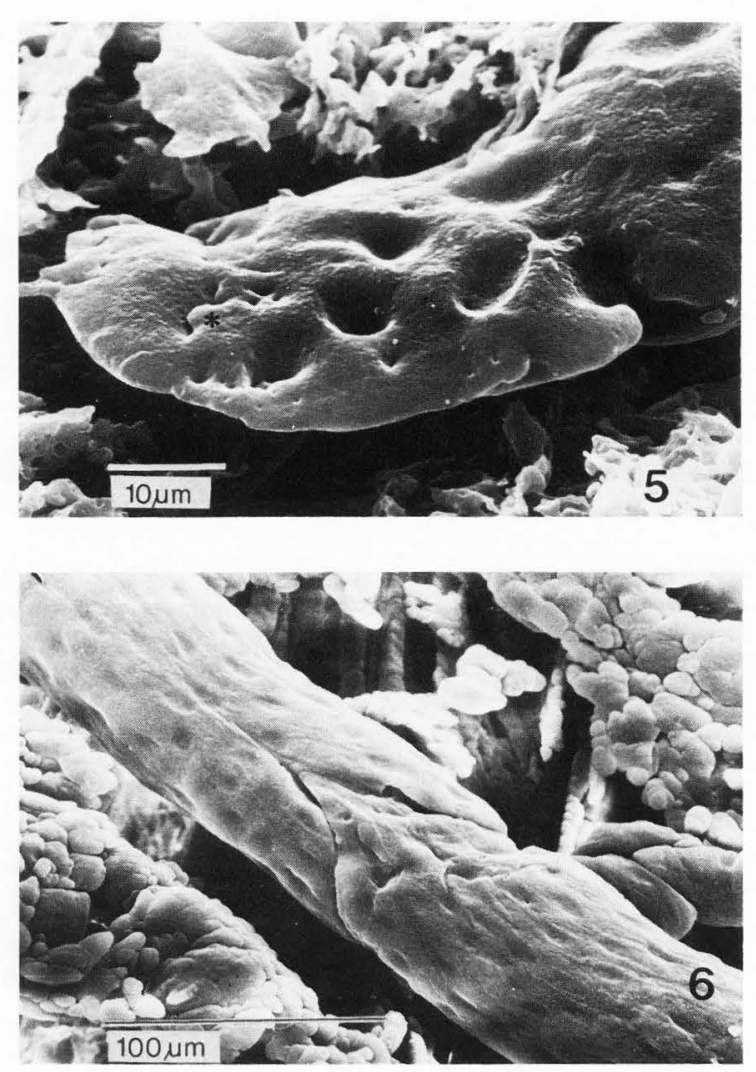

Fig. 1. General organization of the lymph vascular system.

Fig. 2. Corrosion cast of the tongue of a 19-day-old fetus. View from the underand lateral side. The interstitial spaces of the tongue body and the subepithelial lymphatics are filled with Mercox ${ }^{R}$ after interstitial injection.

Fig. 3. Cast structures occurring in the loose collagenous fiber tissue of the subepithelial layer of the rat tongue (corrosion cast of a newborn animal).

Fig. 4. Subepithelial plexus of initial lymphatics in the tongue of a 7-day-old rat. Note the blind, sac-like outpocketings (*) and the great variety of the vessels' calibers.

Fig. 5. Surface profile of cast structures of an initial lymphatic in the tongue of a young rat. Ball- and ovalshaped impressions are produced by strongly protruding endothelial cells. At other sites lip-formed extensions (*) of the resin exist indicating overlapping structures of the interendothelial border system.

Fig. 6. Cast of a precollector vessel of the subepithelial lymphatic plexus in the tongue of a young rat. The regular imprint pattern of endothelial nuclei as well as the V-shaped indentations of a bicuspid valve are well visible. 
cast pattern of the initial lymphatics and that of the interstitial spaces can seldom be observed in our preparations. Therefore it is hard to judge whether they represent an open communication between the prelymphatic tissue channels and the lymphatic pathways or whether they are of artificial nature.

In good preparations the morphological characteristics of the initial lymphatic vessels are reflected on the surface of cast initial lymphatics. Thus, the imprint patterns of the zone of the protruding endothelial nuclei and of the system of the wavy endothelial borderlines with deep indentations and extending flaps become apparent (fig. 5). These cast structural features can be brought in relation to the special morphology of the lymphatics which exhibit an endothelial system with numerous overlapping structures functioning as simple valves and with types of protruding branched cells $2,4,6$. Casts of vessels of the precollector type exhibit a more regular imprint pattern of the endothelial nuclei and are indented at some sites by the impressions of valves mostly of the bicuspid type (fig. 6).

\section{Lymph Nodes}

After interstitial (subcapsular) injection of Mercox $\mathrm{R}$ into the lymph node the resin easily penetrates into the sponge-like node tissue filling the system of sinuses and also parts of the intercellular spaces of the reticular stroma. On the surface of the preparations the cast of the marginal sinus appears covering the deeper located structures like a screen. Casts of the extranodal lymph vessels, particularly the Vasa efferentia, which arise at some sites of the marginal sinus system become apparent in many preparations (fig. 7). These structures exhibit the morphological features of the collecting lymph vessels which can also be seen in other regions of the lymph vascular system (see below).

Incomplete casts of a lymph node give a view of the radially orientated structures of the intermediary and medullar sinuses. In some preparations these structures are surrounded by irregularly shaped figures belonging to the spaces of the lymphatic reticulum. The cast surface of the intranodal sinuses themselves shows a strong roughness. This phenomenon is produced by the irregular nature of the sinus wall from which in tissue preparations numerous branched cells protrude partially or totally into the sinus lumen (fig. 8).
Collectors, Lymph Trunks, Thoracic Duct The bigger collecting lymph vessels including the thoracic duct have a segmental organization which is clearly recognizable in the cast preparations (fig. 9). Each segment marked by a proximal and distal valve can be regarded as a functional unit ("lymphangion") 15. Two deeply incising notches in the casts correspond to the lips of a bicuspid valve. The slit axis of the bicuspid valve alternates segment by segment in the course of a collecting vessel as it can be demonstrated by the changing orientation of the notches in the casts. A regular arrangement of the valves is not recognizable in the bigger lymph trunks and the thoracic duct, as it can be found in smaller collecting lymph vessels. Few or no valve structures are exhibited in the casts of the mesenteric cisterna.

The vascular portion between the valves exhibits a luminal figure with imprint patterns of endothelial nuclei on its surface. Additionally, some casts show circularly orientated weak indentations obviously belonging to the smooth muscle system of the vessels' media. Within a valve region of the cast of a bigger lymph collector the sectional area moulded by the proximal surface of the valve lip is convex and smooth, that of the distal lip surface has a concave form and reveals a pattern of fine impressions caused by the nuclear protrusions of the lip endothelium (fig. 10).

\section{Discussion}

It is generally possible to demonstrate all divisions of the lymphatic vascular system by corrosion casts in SEM. Due to its special organization, however, comprising the initial vascular system, the intranodal lymph pathways, and the system of the collecting trunks, special techniques have to be applied to get good preparations from these particular structures. The initial lymphatics are made visible in tissue casts after interstitial injection of resin. The high permeability of the vascular wall of this kind of vessel obviously allows the liquid resin a nearly free passage into the lumen. In the skin and mucous area of some organs, like the subepithelial zone of the tongue, a complete or nearly complete filling of the initial lymphatic system is possible by only one interstitial injection. The method also allows filling of some of the precollecting vessels exceptionally also collectors or prenodal lymph vessels draining the lymph off from the tongue.

The question to what extent the cast figures outside of the vascular structures show the prelymphatic spaces, as 
already discussed above, is somewhat difficult to decide. Although there is not much doubt that the cast pattern of regularly shaped figures in the loose connective tissue contains prelymphatic pathways it cannot be excluded that the dimensions of single figures might be artificial. After high pressure interstitial resin injection especially the spaces become widened and filled with the resin which is not the case under normal conditions. Thus, further quantitative SEM investigations should be carried out by which the number and dimension of the cast channels structures are measured and compared with the parameters previously found by other authors who used precipitated ferric salts to outline the interstitial spaces ${ }^{1}, 3$. Also, the direct connections between the cast figures of the interstitial system and those of the initial lymphatics occasionally observed in our preparations should be carefully judged. They cannot be the evidence for an open circulation at the beginning of the lymph vascular system.

The intranodal injection of Mercox ${ }^{R}$ causes a quick penetration of the resin into the labyrinth of the intranodal sinuses and the interstitial spaces of the reticular tissue. To get a complete filling state of a cast of a lymph node with all tissue compartments accessible for the resin, attempts can be made by perfusion of the node with a physiological solution before the resin is applied. By such a pretreatment the numerous free cells are removed from the spatial system of the reticular tissue which now can take a higher amount of resin. The danger of an overfilling effect of the node tissue seems not to be great as the node capsule prevents a too strong extension and disruptions of the tissue. The best method of filling the bigger lymph channels in the last part of the lymph vascular system is the intraluminal application of resin. Those injections should be made with a moderate pressure, if done by hand, to avoid artificial extension of the vessels. In a state of such a high extension the small notches marking the valve zones become straightened and get a more basin-shaped profile.

Summarizing, the microcorrosion cast technique proves to be a very suitable tool in lymph angiology. Casts cannot only give information on the general vascular arrangement of the lymph pathways but also on the morphological details imprinted on the cast surface. SEM of lymphatic casts enables one to observe the vascular structures at low and high levels of magnification as well as in a three-dimensional manner. It enlarges our knowledge of these delicate structures which for a long time could have only been drawn from light and transmission electron microscopical studies.

\section{References}

1. Browning J, Casley-Smith JR (1981). Tissue channel morphology in Octopus. Cell Tissue Res. 215, 153-170. 2. Casley-Smith JR (1964). Endothelial permeability - the passage of particles into and out of diaphragmatic lymphatics. Quart. J. Exp. Physiol. 49, 365-383. 3. Casley-Smith JR, Vincent AH (1978). The quantitative morphology of interstitial channels in some tissue of the rat and rabbit. Tissue and cell 10 , 571-584.

4. Castenholz A (1984). Morphological characteristics of initial lymphatics in the tongue as shown by scanning electron microscopy. Scanning Electron Microsc. 1984; III: 1343-1352.

5. Castenholz A (1984). Strukturbild und Wirkungsweise der "initialen Lymphbahn". Z. Lymphol. VIII, 55-64.

6. Castenholz A (1985). The demonstration of lymphatics in casts and fixed tissue with the scanning electron microscope, in: The Initial Lymphatics. New Methods and Findings, International Symposium Zurich 1984, Bollinger A, Partsch H, Wolfe JHW (eds.), G. Thieme/ Thieme-Stratton Inc., Stuttgart-New York, $70-78$.

7. Castenholz A (1985). REM-Darstellung von interstitiellen Raumsystemen und Lymphbahnen mit der Kunststoffinjektion . GIT Suppl. 2, 16-21.

8. Castenholz A (1985). The endothelium of initial lymphatics during postnatal development of the rat. Scanning Electron Microsc. 1985; III: 1201-1208.

9. Castenholz A (1985). Observations on the structural and functional properties of initial lymphatics - light and electron microscopic studies of the subepithelial lymphatic plexus in the rat tongue, in: Progress in Lymphology, X. Proc. Int. Cong. Lymphology, Adelaide, 1985, Casley-Smith JR, Piller NB (eds.). University of Adelaide Press, 20-23.

10. Castenholz A (1985). SEM representation of initial lymphatic structures in early stages of ontogenetic development in rat, in: Progress in Lymphology, $\mathrm{X}$. Proc. Int. Cong. Lymphology, Adelaide, 1985, Casley-Smith JR, Piller NB (eds.), University of Adelaide Press, 24-26.

11. Karaganov I, Mironov AA, Mironov VA, Gusev SA (1982). Scanning electron microscopy of corrosion preparations. Arch. anat. gistol. embriol. 81, 5-21. 12. Kobayashi S, Osatake H, Kashima Y (1976). Cossorion casts of lymphatics. Arch. histol. jap. 39/3, 177-181. 
A. Castenholz
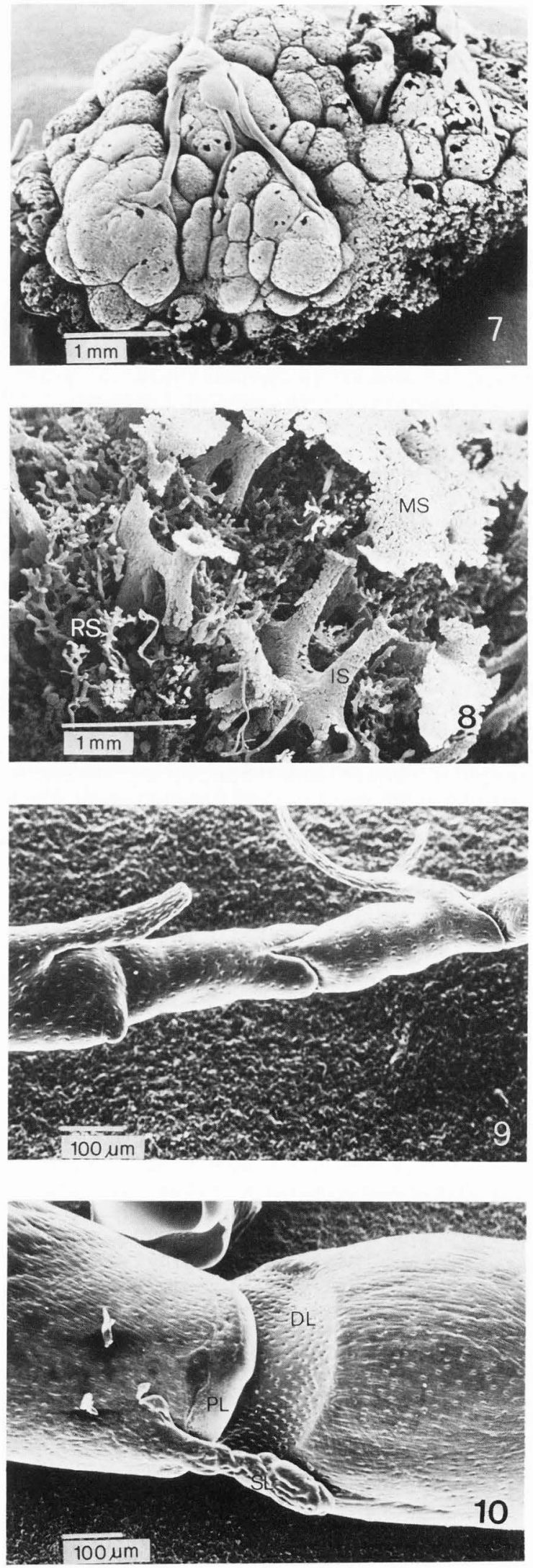

Fig. 7. Corrosion cast of a mesenteric lymph node in rabbit. On its surface the sheet-like filling structures of the marginal sinus with some efferent vessels (Vasa lymphatica efferentia) appear.

Fig. 8. Cast preparation of a mesenteric lymph node with an incomplete filling allowing a view on the inner organization of the intranodal lymph pathways.

$\mathrm{MS}=$ marginal sinus, $\mathrm{IS}=$ intermediary sinus, $\mathrm{RS}=$ spaces of the reticular tissue.

Fig. 9. Cast of a bigger lymph collector from the mesenteric root in rabbit. Deep notches produced by the valves mark the lymphangions of the vessels. Some smaller branchings are also noticeable.

Fig. 10. Cast of a bigger lymph collector showing some details of the valve region: DL = print area of the distal, $\mathrm{PL}=$ of the proximal surface of a valve lip, SL = branch of a smaller lymph vessel. Note also the imprint pattern of the endothelial nuclei.

13. Konitz H, Berens $\mathrm{v}$ Rautenfeld D, Klanke J, Wenzel-Hora B (1985). REMDarstellung der initialen Lymphstrombahn durch indirekte Applikation von Mercox ${ }^{R}$ oder Gluaraldehyd. Beitr. elektronenmikroskop. Direktabb. Oberfl. 18 , 249-256.

14. Lametschwandtner A, Lametschwandtner U, Weiger T (1984). Scanning electron electron microscopy of vascular corrosion casts - technique and applications. Scanning Electron Microsc. 1984; II: $663-695$.

15. Mislin H (1983). The lymphangion, in: Lymphangiology, Földi M, CasleySmith JR (eds.), Schattauer, StuttgartNew York, 165-175.

16. Tamura A, Kurokawa T, Yamada S, Nishiyama M, Sakamoto T, Sato T, Kinoshita S, Chikasawa N, Yoshii Y, Takata S, Tamura S, Ogata T (1978). Scanning electron microscopic studies on the lymphatic vessels of the rat stomach. J. Clin. Electron Microsc. 11, 426-427. 17. Vyrenkov YuE, Kataev SI (1983). Microcirculatory bed of the liver as evidenced by the data of scanning electron microscopy. Arch. anat. gistol. embriol. 84, 61-70.

\section{Discussion with Reviewers}

K.C. Hodde: What is the basic idea now of the continuity/discontinuity between interstitial tissue space and initial lymphatics?

Author: This question gave reason for many discussions among morphologists and histophysiologists until in 1863 
von Recklinghausen regarded the beginning of the small lymphatics as open connections to the tissue spaces and His, in contrary to him, considered the lymphatics united in a close channel system. The present methodical study is not able to give a definite answer to this problem. Hence, please refer to the literature in which the question of the origin of the lymphatics is treated under different morphological, ontogenetic, and phylogenetic aspects (e.g. Rusznyák J et al. (1969). Lymphologie, Physiologie und Pathologie der Lymphgefäße und des Lymphkreislaufes, Gustav Fischer Verlag, Stuttgart. Földi M, Casley-Smith JR (1983). Lymphangiology, Schattauer Verlag, Stuttgart-New York).

K.C. Hodde: Are the outpocketings in figs. 4 and 5 the closest you have come to depict the beginning of initial lymphatics?

Author: The outpocketing structures we see in our casts of the rat tongue have mostly the dimensions of the cast figures shown in the mentioned figures. Those with a more bulb-like appearance and larger diameters as they have been observed in the bat wing by Webb and Nicoll (Behavion of lymphatic vessels in the living bat. Anat. Rec. 88, 361-387 $(1944))$. do not seem to occur in the tongue.

K.C. Hodde: Do you have results of lymph casts after perfusing the nodes with saline before casting?

Author: If the node is pretreated in such a way, the intranodal spaces are frequently more completely filled than the non-perfused preparations. However, we could not recognize any differences between both preparations in regard to the morphological features of the intranodal pathways.

K.C. Hodde: Did you do any correlative histology of injected tissue to see the extent of filling as you have done previously with blood vessel casts? Author: We have not yet made correspondent correlative histologic studies as done with cast blood vessels in different organs like liver, kidney, suprarenal gland, and skeletal muscle (Castenholz A (1983). Scanning Electron Microsc. 1983; IV: 1955-1962); But it would, of course, be advisable to start such a study in the future.

K.C. Hodde: What was your reason for fixing the tissue after injecting the plastic just before maceration?

Author: It is not absolutely necessary to do this procedure. But, as we cannot be sure that the process of polymerization is delayed in certain sections of the cast preparations, e.g. by dilution of the resin with saline, lymph or interstitial fluid, we think it necessary to take these steps in order to avoid artefacts which could probably occur in unfixed tissue.

A. Lametschwandtner: How deep is the injection needle introduced into the tongue when you do the interstitial resin injection for casting the initial lymphatics?

Author: We insert the needle deeply into the central part of the tongue body from which the resin - especially after a weak massage - can spread in all directions of the stromal tissue to reach at last also the subepithelial zones in the upper, lower, and lateral side of the organ with the initial lymphatics.

A. Lametschwandtner: Does it happen that you cast also blood vessels if doing interstitial resin injections?

Author: Casting of both the blood vessel system and the lymphatic system after interstitial application of the resin may occur if the needle is placed accidentally into a bigger blood vessel. Such a situation, however, does not often take place and if so, the casts of the blood vessels can easily be distinguished from those of the lymphatics. We dispose of preparations with double fillings of both systems after combined interstitial and arterial injections of the resin which can well be differentiated in this regard. 
